\title{
Mixed messages from Europe on Drug Policy Reform: the cases of Sweden and the Netherlands
}

\author{
Dr Caroline Chatwin, University of Kent
}

\begin{abstract}
This article examines the variety of drug policy in operation within Europe by focusing on Sweden (relatively restrictive) and the Netherlands (relatively liberal) as casestudies. It analyses European data to produce an in-depth overview of the nature of the illegal drugs situation in both countries, focusing on both successes and areas that could be improved. Finally it appraises the appetite for drug policy reform in terms of (i) cannabis regulation and (ii) treaty reform in each country. The main conclusions suggest that there are no common indicators of success by which drug policies in general can be judged, and there is little agreement within Europe about whether or not we are in need of drug policy reform. It suggests that a successful global drug policy should celebrate diversity and should also seek to provide an international framework within which different global drug strategies can be evaluated."
\end{abstract}

\section{Introduction: Divided Opinion on Drug Policy in Europe}

All European member states are signatories to the United Nations (UN) conventions on illicit drugs pledging to pursue a prohibition-oriented approach to certain psychoactive substances, yet opinion within Europe on the correct approach to drug policy varies widely. In the late 1980s and early 1990s the European Parliament launched two commissions to investigate these different approaches toward illicit drugs, with a view to establish a European standpoint. The results of both commissions, however, were inconclusive and the principle of subsidiarity was invoked in this area - meaning that illicit drugs remain an issue ultimately controlled at the national, rather than the European, level. In accordance with this principle, the European Union (EU) currently plays a guiding role in developing a coherent framework for drug policy within which different European member states are relatively free to develop their own responses. Individual member states and European officials generally agree that drug trafficking and drug traffickers should be treated relatively seriously with, in most cases, lengthy prison sentences (although disputes remain over which substances should be prioritized and what 
constitutes a significant amount of any particular substance) and agreements have been reached about minimum-maximum penalties (the lowest maximum penalty allowed) for drug trafficking offenses.

In the arena of drug use and drug users, however, a much greater policy disparity exists; this can be imagined on a spectrum from relative liberalization to relative repression. Analyzing the drug policies of the Netherlands (relatively liberal) and of Sweden (relatively repressive) - European Union (EU) member states at either end of the drug policy spectrum - exemplifies these differences. It is the intention of this paper to assess the existing drug policy contexts in Sweden and the Netherlands, as well as each country's appetite for drug policy reform. A picture can then be assembled of the breadth of drug policy experience within Europe, the deep divisions in opinion over what can be deemed "a successful" drug policy, and the consequences for providing a European perspective in debates over the future of drug policy reform.

\section{Sweden and the Netherlands: The Policy Context}

In Sweden, with its strong welfare state, and long-established strict alcohol policy, which has generally been regarded as relatively successful, drug policy is controloriented and moralistic, operating as a cross-political party issue where the policy is endorsed by wider society in its entirety. The ultimate aim is to achieve a drug free society (Ministry of Health and Social Affairs, 2010), which has resulted in a stricter policy than that of most other European countries. National drug laws do not make a distinction between soft and hard drugs depending on harm; in fact, cannabis use is treated seriously as it is considered a "gateway" to the use of other drugs. Alterations have been made to prohibit the consumption as well as possession of drugs, with police officers authorized to issue blood or urine tests to determine whether use has taken place. Policing strategies ensure that drug users are targeted with as much vigor as drug dealers and traffickers. Membership of the European Union now requires that minimum levels of harm reduction measures (needle distribution/exchange programs and maintenance treatment programs) toward drug users are offered. The number of these programs available in Sweden, however, remains tightly restricted, and abstention-based treatment methods (including those that are coercive) are preferred. As a result, the illicit drug situation in Sweden has become entwined with national identity, with the life of the dependent drug user being held up as the antithesis of the life of a good citizen (Tham, 1995). Illicit drugs have also been conceptualized as a problem that has come from outside Sweden and which constitutes a threat to the Swedish lifestyle (Gould, 1994). Illicit drugs have therefore become an issue that supersedes party 
political interest. Current policies toward them are generally considered to be successful and no official appetite for drug policy reform exists.

In the Netherlands, meanwhile, since the late 1960s, national drug policy has accepted the inevitability of some drug use within society and has therefore aimed to normalize the users of illicit substances, rather than to eradicate them from society. As such, harm reduction and low threshold services have been prioritized, with the Netherlands pioneering needle exchange programs and maintenance treatment in Europe. Remaining at the forefront of harm reduction developments, the Netherlands also offers some dependent heroin users legal prescriptions of heroin, provides "safe user rooms" for dependent drug users to consume their drugs, and is at the forefront of developing cannabis for medicinal use in Europe. National drug prevention strategies target the dealers and traffickers of drugs rather than the users and prosecute only instances of drug possession (rather than consumption), and even then prosecution is rare. Importantly for the considerations made later in this paper, the Netherlands is often thought of as being at the forefront of drug policy reform due to its unique strategies that aim to separate the markets between cannabis and other drugs that are considered more harmful.

Since the 1970s, the use and sale of small amounts of cannabis has been tolerated in the Netherlands under the principle of expediency, which designates that while the sale and possession of cannabis remain illegal, it is never in the public interest to prosecute where relatively small amounts are concerned; this is an attempt to operate within the confines of UN conventions on illicit drugs. This policy distinction has allowed a system of commercial premises, where the sale and open use of cannabis products is tolerated, to emerge organically. These premises are known as "coffeeshops" and are regarded by many as having been successful in "separating the market" for cannabis from the illegal markets in more harmful illicit substances, such as heroin or crack cocaine. Over the years, coffeeshops have been subjected to increasing regulations. For example, cannabis can be sold only to those aged 18 and over, restrictions have been placed on the amount of cannabis that can be sold to an individual customer at one time ( 5 grams) and that can be kept in a coffeeshop (500 grams), and coffeeshops are not allowed to advertise themselves, to cause undue public nuisance, or to permit the sale of any illicit drugs other than cannabis. Significant inconsistencies remain, however, as there is no provision for the supply of cannabis to coffeeshops. While "front door" sales have been legitimized, the "backdoor" cultivation of cannabis remains wholly a part of the illegal market. The coffeeshop policy has long attracted external criticism and is now subject to internal attempts to further restrict the trade in cannabis. For example, the current government has made attempts, though not entirely successful ones, to limit the sale of cannabis to Dutch citizens in an effort to curb drug tourism, 
and has stated its intention to disallow sales of cannabis that have a 15 percent or higher tetrahydrocannabinol (THC) content. While recognizing the problems inherent in the Dutch approach, and despite recent attempts from the government to increase controls, the majority of the public favor extending the regulation of the cannabis market (Peil.nl, 2013).

These brief presentations of illicit drug policy in Sweden and the Netherlands demonstrate the emergence of two distinct, simultaneous paradigms of drug control in Europe: the liberal, pragmatic policy of the Netherlands with the primary aim of harm reduction for the users, and the more moralistic and restrictive zero-tolerance policy of Sweden that aims to eradicate drug use from society. A historical exploration of drug policy reveals a deep-seated and enduring commitment to national drug policy in the two countries, which sit at either end of the drug policy spectrum within the EU (Chatwin, 2011). These factors make it almost impossible for the EU to adopt a common position on the desirability of drug policy reform.

\section{Sweden and the Netherlands: The Situation on the Ground}

This section describes trends in illicit drug-related issues in Sweden and the Netherlands. Areas examined include: the prevalence of drug use and of dependent drug users, drug-related death and disease, treatment and low-threshold services, and crime and organized crime. The statistical information on which this section is based, unless stated otherwise, is taken from the individual national annual drug reports of Sweden and the Netherlands, the annual report on the drug situation in Europe produced by the European Monitoring Centre for Drugs and Drug Addiction (EMCDDA), and from tables of comparative data and individual country profiles freely available from the EMCDDA website (EMCDDA, 2014; van Laar et al, 2013; Sweedish National Institute of Public Health, 2012). It is also the aim of this section to identify remaining challenges for each country's illicit drug policy.

\section{Sweden}

Swedish authorities have consistently reported a relatively low prevalence of illicit drug use within the general population. In the most recent figures, 15 percent of the general population reported having used cannabis at least once in their lifetime; the Swedes remain below the EU average (21.7 percent). Earlier figures for other substances show similarly low levels of prevalence. It is worth noting here, however, that while prevalence figures may be impressively low, drug users are a significantly stigmatized group within Sweden and reluctance to admit to being a drug user may therefore be impacting these figures.. Interestingly, while many European countries have reported a decline in overall drug use over the last few 
years, and particularly in cannabis use, Sweden has seen small increases in these areas.

There is no single European-wide definition of dependent drug use so making comparisons in this area can prove difficult - for example, data can be gathered on opiate users, on injecting users, on those in treatment, or those in prison.Nevertheless, data from Sweden shows that - unusually for Europe - the primary drug associated with dependence and injecting is amphetamine. The number of dependent users (most recent estimates suggest around 30,000 people) and injecting users (most recent estimates suggest around 8,000 people) in Sweden are quite high considering the low number of people who have tried drugs in general. This means that a fairly high proportion of people who try drugs such as heroin and amphetamines go on to become problematic in their use.

The number of drug-related deaths reported in Sweden (62.6 per million people) is more than three times the European average (17.1 per million people), and the most recent data shows that drug-related deaths are increasing. In contrast to some other countries, and the EMCDDA standard definition, Sweden also includes deaths in which drugs have played a contributory cause, and this may pay some part in their inflated figures here. Levels of HIV are stable, but hepatitis B and C are comparatively high, with one source describing a recent epidemic of hepatitis $\mathrm{C}$ among injecting drug users in Stockholm (Barrett, 2014), and various studies conducted during the last 15 years showing very high levels of hepatitis $\mathrm{C}$ among injecting drug users more broadly. Although the total number of reported cases is decreasing, this data indicates an ongoing recruitment of young people to injecting drug use, and an ongoing transmission of the disease among young intravenous drug users in Sweden.

Sweden offers virtually no low threshold drug treatment services, concentrating its resources instead on abstention-based treatment programs and coercive treatment programs. New clients in treatment are primarily users of cannabis and amphetamine, and most injecting clients are amphetamine users. The prevalence of both needle exchange programs and maintenance treatment programs has increased recently, but this type of treatment remains at low levels compared to Western European standards (although Eastern Europe has even lower provision levels of these services) (EMCDDA, 2010).

Perhaps unsurprisingly, Sweden records a relatively high number of offenses against the drug law in comparison with the European average. Longitudinal data suggests that the number of offenses recorded is increasing, with 2012 data showing a 6 percent increase from 2011. 
Levels of organized crime, political corruption and violence associated with drug markets are very low. It is estimated that 90 percent of illicit drugs come into Sweden from abroad and that the most common method of drug trafficking is via the postal service. There is evidence of some professional scale cannabis cultivation in the south of the country, but this is on a relatively small scale compared to other European countries.

Proponents of Swedish drug policy have been quick to point to the low prevalence of drug use in the country as evidence of its successful nature in general. The UN report, Sweden's Successful Drug Policy: A Review of the Evidence, praises the country for its uniformly negative attitudes toward drug use and attributes these low levels to a uniformly restrictive drug policy (UNODC, 2007). Others have been more critical and point to dangerously high levels of drug-related death and disease, which are particularly concerning given the generally low levels of drug use prevalence (Cohen, 2010). A remaining challenge for Swedish drug policy is the high proportion of heavy drug use, and the poor health and longevity of drug users. There is limited evidence that Sweden is attempting to address these issues, although the latest national report on the drug situation does emphasize a commitment to tackling social exclusion, which lies at the heart of much drug use.

\section{The Netherlands}

Data on the prevalence of drug use in the Netherlands records that 25.7 percent of the general population reported having used cannabis at least once in their lifetime, which is slightly above the European average ( 21.7 percent). Historical data demonstrates that levels of cannabis use have increased since the introduction of the "separation of the markets" (coffeeshop) policy, but that these increases have been in line with European trends. Most recent estimates of lifetime prevalence of ecstasy use in the Netherlands are 6.2 percent, which is nearly twice the European average (3.2 percent). Despite the high levels of ecstasy use, some supporting evidence for the success of the "separation of the markets" policy comes from a survey in which just 14 percent of cannabis users in the Netherlands report that other drugs are available from their usual cannabis source (compared to 52 percent in Sweden) (Rolles, 2014).

In 2013, the number of problematic opiate users was estimated at 14,000 (3.1 per thousand people), which suggests a decrease of 21 percent compared to the previous estimate for 2009. These rates are lower than those of many other European countries. Furthermore, the data demonstrates an ageing of the dependent drug user population, which indicates that fewer young people are becoming dependent on 
drugs. The number of injecting drug users is also declining in the Netherlands, with recent figures suggesting that only 7 percent of opiate users have recently injected the drug - the lowest rate in all of Europe. These results provide clearer evidence of success of the "separation of the markets" policy, which aims primarily to keep the cannabis market detached from the market for more harmful drugs such as heroin.

The number of drug-related deaths in the Netherlands remains low: 10.2 per million people. Mortality comparisons must be made cautiously because drug-related death is defined differently across Europe; however, these figures are low in terms of European averages (17.1 per million people) and have been ratified by the EMCDDA as being at low risk of underreporting. A decreasing percentage of the deceased were aged 25 years and younger, which supports the contention that the Netherlands has an ageing population of dependent drug users, and that fewer young people are becoming dependent drug users. Levels of HIV, hepatitis B, and hepatitis $\mathrm{C}$ infections are also generally low in the Netherlands with only 5 percent of HIV infections associated with injecting drug use, and a very low ( 0.4 per million people) incidence of HIV among injecting drug users. Recent data indicates a substantial increase in the number of people seeking medical treatment for ecstasyrelated emergencies, and suggests an increase in the average MDMA concentration in ecstasy tablets in recent years.

Recent analyses of Dutch illicit drug treatment data show no clear trends over the past few years. From 2002 to 2010, the annual number of new clients applying for help at drug treatment services varied between 8,000 and 11,000 people. Since the late 1960s, the Dutch government has invested in comprehensive health and social services that aim to reduce the amount of individual and social harm caused by illicit drug use. Low threshold treatment services, maintenance treatment programs, needle exchange programs and, more recently, safe consumption rooms all proliferated earlier in the Netherlands than in most other European countries and now enjoy a higher coverage than in most of Europe.

Although the overall number of Opium Act cases dealt with by the police, public prosecutor, and courts increased in 2012, arrests and convictions for possession of illicit drugs are very low in the Netherlands compared to other European nations. Arrests resulting in criminal records for cannabis possession are extremely rare in the Netherlands.

Levels of political corruption and violence associated with illicit drug markets are low, but there is some evidence of national drug production and an association with organized crime networks. In 2012, 5,773 cannabis cultivation sites were 
dismantled, 42 production locations for synthetic drugs were dismantled, 66 storage locations were discovered, and 68 incidents of dumping of the chemicals involved in synthetic drugs production were reported. Organized crime related to cocaine, heroin, synthetic drugs, and large-scale professional cultivation of cannabis have been defined as priority areas for policy enforcement for the period 2013-2017.

Supporters of Dutch drug policy point primarily to its successes in two areas: (1) the low number of dependent drug users, the low number of injecting drug users, the low number of drug-related deaths, the low levels of HIV and other infectious diseases found among the drug using population, and the ageing of the dependent drug using population; and, (2) the effective nature of the "separation of the markets" policy, citing statistics that show low average cannabis use levels among the general population (both in absolute terms and relative to many countries that do not employ a coffeeshop system), as well as low levels of dependent drug use. The low levels of arrests and criminal records related to the possession of illicit drugs have also been commended. Current problems include the levels of ecstasy use, the strength of ecstasy found within the Netherlands, the involvement of Dutch people in the cultivation of cannabis and the production of synthetic drugs including for export to other countries - and the public nuisance and drug tourism associated with the coffeeshop system.

Coffeeshops are concentrated in large cities in the north of the country and attract many non-Dutch visitors, particularly in border regions. There are also concerns about the involvement of criminal organizations in cannabis cultivation and wholesale supply (which remain illegal in the Netherlands, despite the decriminalization of use). Limited available evidence suggests, however, that these are not particularly violent markets; for example, the Dutch murder rate has remained stable and, in global and regional terms, low level of around 1 percent over the last 10 years. The reforms to coffeeshop policy outlined in the previous section were introduced in part to effect a reduction of drug tourism and public nuisance; but, as we shall see below, they have not been either entirely successful or entirely popular.

\section{Policy Effectiveness and Recommendations for Reform}

Judging the relative success of different European drug strategies has long been of interest to European scholars and institutions involved in exploring the illicit drug problem. Since 1995, the European Monitoring Centre for Drugs and Drug Addiction (EMCDDA) has been collecting and disseminating statistics on the nature of the illicit drug problem in different European Union member states; it is largely on these efforts that the data presented above is based. This data collected 
by the EMCDDA is not perfect; cross-national comparative research conducted on this scale is hampered by different research methods and cultures. Additional problems include scarce and poor quality data from many member states, as well as the inherent problems faced when attempting to uniformly define complex concepts such as drug-related death, disease, or crime. The quality of their work, however, represents a gold standard of data collection of its kind in a global arena.

Nevertheless, efforts to use the data collected by the EMCDDA to evaluate which is the most successful existing drug strategy in Europe have been hampered by two thus far insurmountable problems. First, no common indicators of "success" exist regarding the illicit drug problem. Supporters of Swedish drug policy draw on the uniformity and totality of their approach toward illicit drugs, the generally low levels of prevalence of drug use within their society, and the low levels of crime, violence and illicit drug production, to confirm their "success" in this area. Meanwhile, supporters of a Dutch style policy point to the effective separation of the markets they have achieved between cannabis and other drugs, as well as the inroads they have made in reducing the harm to drug users in terms of death, disease, and involvement with the criminal justice system, as evidence of their own "success." The above example therefore suggests that it is relatively meaningless to talk in terms of 'success' in drug policy while there is no consensus about whether success is defined by low prevalence of overall drug use, by the health and longevity of existing users, or by some third factor. Second, a full appraisal of data related to the illicit drug problem fails to show any relation between the style of drug policy and the size or nature of the drug problem (Chatwin, 2011; Reinarman et al, 2004). Persuading national governments to abandon policies that have been in practice for some 50 years or more and adopt instead policies that are fundamentally different is therefore a very difficult task.

Given these two different paradigms of illicit drug policy in operation, it has been consistently difficult for European institutions to engender a harmonized European drug policy or to present a united front in global debates about drug policy reform. Despite the differences outlined above, there are some important similarities in Swedish and Dutch drug policy that are also shared by most European countries. For example, political corruption and extreme drug market-related violence tend not to be significant problems; drug production tends to be confined to cannabis cultivation and the production of synthetic drugs; and drug trafficking is treated severely, at least in Western terms.

But the Swedish and Dutch approaches to the control of illicit drug use and drug users are fundamentally incompatible. Because of these differences, in line with the European Union in general, and specifically its monitoring center in Lisbon, this 
paper declines to enter the debate on the relative merits of individual national drug strategies. While remaining on neutral territory, the EU has played a guiding role in developing a framework within which national drug policy has developed, and the monitoring center has strongly encouraged and effected the evaluation of individual drug control measures, the convening of cross-national networks of experts, and the sharing of best practices. Under this guiding framework, many very different responses to the drug problem (the zero tolerance approach of Sweden, the coffeeshops of the Netherlands, the decriminalization of possession for personal use of all drugs in Portugal, and the cannabis clubs that began in Spain) have been allowed to bloom in an effort to find effective responses to the use and supply of illicit drugs.

\section{Mixed Messages from Europe on Policy Reform}

In recent years, many voices from around the globe have challenged the continuing validity of the existing UN drug conventions, particularly in light of cannabis regulation systems emerging in the U.S. states of Colorado and Washington, and in Uruguay. This section examines the Swedish and Dutch positions on the reform of UN conventions and the implementation of a fully regulated cannabis market.

The view from Sweden is relatively simple: drug policy remains a cross-party political issue and the prevailing feeling, endorsed by the UNODC report Sweden's Successful Drug Policy, is that there is no reason to amend the relatively restrictive policy strategies that have been employed to date. Each of the main political parties is in agreement that the ultimate vision of "a drug free society" should remain. Therefore, there exists no legitimized discussion on the relaxation of cannabis laws in the form of the decriminalization of possession for personal use, the allowance of a small number of plants cultivated for personal use, or the introduction of cannabis clubs or collectives where medium-scale cultivation of cannabis is tolerated, as has been observed in other European countries. In terms of the UN drugs conventions, Sweden and the United States hosted a meeting during the UN Commission on Narcotic Drugs High Level Segment in 2014 with other countries (Italy, United Kingdom, France, Australia, New Zealand, and Canada) that sought to preserve the existing three UN drug control conventions and to discuss a strategy of continuing support for the conventions. Maria Larsson, the Swedish Minister of Health for Children and the Elderly, expressed Sweden's strong support for balanced policies under the three UN conventions (Office of National Drug Control Policy, 2014). 
The situation in the Netherlands is more complicated as opinions are not universal and as such, no formal stance on the reform of the UN conventions has been expressed. In terms of the cannabis market, the recent Dutch reforms and proposed reforms to the coffeeshop system (the partial implementation of the limitation of cannabis sales to Dutch citizens who are registered as members of a particular shop, and the plans to restrict sales of cannabis with a THC content greater than 15 percent), as well as the decreasing number of coffeeshops seen recently in the Netherlands in general, have led some to believe that the Dutch are undergoing a tightening of cannabis policy. This has been attributed to the fact that the Dutch have experienced a high degree of drug-related tourism which, among other factors, has contributed to a decreased tolerance for the public nuisance that can be caused by a popular coffeeshop or by a liberal national drug policy in general (Garrettsen et al, 2003; Goldberg, 2005) .

Despite these increasingly restrictive measures that have been largely implemented under a right-wing government and a conservative drugs minister, the evidence suggests there is significant support by the general public and local government for more radical cannabis policy reform. While the Netherlands already operates a national cannabis policy that has long been viewed as one of the most liberal in the world, critics have been increasingly vocal about the incoherence of regulating the use, possession, and small-scale sales of the drug while the supply of cannabis to coffeeshops remains illegal (i.e., the "backdoor" problem). The cannabis system implemented in Uruguay goes further than that of the Netherlands because it also seeks to regulate the wholesale supply of cannabis; those of Colorado and Washington States go even further by providing systems of relatively unrestricted commercialization. It is worth emphasizing here that the coffeeshop system developed organically in the Netherlands and only covered small-scale sales because it wanted to work within the confines of the UN conventions. The new cannabis regulation systems being implemented in Uruguay and some U.S. states have in part necessitated the current debate over the potential need for reform of the conventions. Cannabis policy reform, under Dutch terms, has therefore centered around a formalization of the "principle of expediency" and its extension to encompass the entire cannabis market. Of course, there is no indication as yet that a full scale regulation of the cannabis market in the Netherlands would lead to an improved situation on the ground. Indeed, the commercialized nature of markets in Colorado and Washington, and the paternalistic market proposed in Uruguay, have attracted criticism of their own (Room, 2014) and some (Uchtenhagen, 2014) have suggested that a global diversity of experiments in cannabis regulation should be viewed as a strength.

Public opinion surveys in the Netherlands have cited increasing levels of support for the full legalization of cannabis. In 2013, 65 percent of those surveyed reported 
that they would be in favor of introducing to the Netherlands the Uruguayan system whereby the production, sale, and consumption of cannabis were all legalized (Rolles, 2014). Forty-one municipalities within the Netherlands have endorsed a manifesto proposing the regulation of cannabis production, and 25 of the 38 largest municipalities have applied to the ministry of justice for permission to experiment with various forms of authorized cannabis production and wholesale supply (Rolles, 2014). These various proposals were turned down by the most recent minister (who resigned on the $9^{\text {th }}$ March 2015 over allegations of misleading parliament about a compensation payment to a convicted drug trafficker in 2001) but are unlikely to disappear from the agenda, given that the majority of supporters of both political parties of the current coalition government are in favor of legally regulating the supply of cannabis. The second largest party in recent polls (the D66 Liberal party) is drawing up draft legislation for the regulated production of cannabis (Dutchnews.nl, 2014).

The two very different views on drug policy reform explored here - both in terms of reform of the UN conventions and of cannabis market regulation - illustrate the deep divide in Europe over these issues. Despite representing opposite ends of the European drug policy spectrum, neither Sweden nor the Netherlands is completely isolated in their national drug strategies and both are relatively assured of the merits of their respective positions. Presenting a united European position on matters of drug policy reform therefore becomes a very difficult issue.

\section{Conclusion: Lessons to be Learned from Europe's Experiences}

From a global perspective, the nature of the illicit drug situation in the Netherlands and Sweden is relatively similar. Both countries are primarily consumer countries; both experience illicit drug use among the general population as well as dependent drug users with the attendant problems of death, disease, and crime; and neither are beset by extremely violent drug markets or drug-related political corruption experienced in places such as Latin America. Yet as the discussion detailed above attests, the strategies each country has employed could not be more different. Sweden has adopted a cross-political party repressive and negative stance on drug use in all its forms, and works toward the ultimate goal of a drug-free society. Plans to display more tolerance toward the use of cannabis and/or cannabis markets in general are not in existence and support for the existing UN conventions is high. The Netherlands has long operated a national drug policy considered to be among the more radically liberal, which accepts the inevitability of some drug use in society and which works toward reducing the harm experienced by drug users. Significantly, the Netherlands has long adopted a semi-regulated cannabis market in an effort to separate the markets between cannabis and other drugs. There is some 
evidence to suggest this system is currently being subjected to new restrictions, but a thorough examination reveals strong support from the general public and local level politicians for extending the regulation of the cannabis market to also encompass wholesale supply.

With the breadth of opinion illustrated here on drug policies in Europe, it has been very difficult for the EU to present a uniform position on global drug-related issues, such as the reform of UN drug conventions. Small increments toward harmonization have been achieved: for example, the introduction of minimummaximum penalties for drug traffickers, and the introduction of minimum standard harm reduction measures across European member states. These achievements, however, do not stand to contribute toward debates over whether laws pertaining to cannabis markets should be relaxed or whether the existing UN conventions need to be redrafted. Nevertheless, the EU's experiences in guiding the creation of an overarching framework, within which national drug policies operate, may provide pertinent contributions to a debate on the continuing role of the UN in guiding world drug policy.

The first contribution is that the variety of European drug policy currently in operation - the zero tolerance approach in Sweden, the coffeeshop policy long operated in the Netherlands, the cannabis clubs emerging in Spain and elsewhere, and the decriminalization of possession of all drugs for personal use effected in Portugal in 2001 - have all been implemented under the existing UN drug conventions. This demonstrates that there is considerable room for maneuver under their current terms. Second, given that no country in the world has been completely, or even significantly, successful in eradicating illicit drugs and their attendant problems from society, the production of a variety of responses to the illicit drug problem can be viewed in a positive light. While no method of drug control has been judged to be ultimately successful, it does not make sense to limit the response options available, particularly where different global geographical locations experience very different expressions of the problem. As the director of the Dutch Addiction Research Centre has recently commented, the systems for regulating the cannabis markets in Uruguay, Colorado, and Washington are all significantly different from each other and from the Dutch model; but it is the very act of comparing these experiences as they unfold that will allow us to develop more effective drug policies in the long run (Grund and Breeksema, 2013).

The success of a global drug policy that allows "many flowers to bloom" requires the freedom of individual countries to be able to choose the national drug policies most suited to their own experiences of illicit drugs and to their own policy making contexts. It also, however, requires the provision of a framework within which 
different global drug strategies can be evaluated, and a network across which the results of those evaluations can be shared. As noted earlier, the European Monitoring Centre on Drugs and Drug Addiction has made commendable efforts in these areas. Lessons from Europe therefore indicate that existing UN drug conventions should not be conceived as an obstacle to allowing individual countries to develop the drug policy responses they feel most appropriate (but should be reformed if they become a such an obstacle). Finally, international bodies such as the UN also have an important role to fill in terms of providing a framework within which national drug policy strategies can be evaluated.

\section{References}

Barrett, D. "On the International Day Against Drugs, Let's Look Again at Sweden's 'Successful' Drug Policies.” Huffington Post, June 26, 2014. http://www.huffingtonpost.co.uk/damon-barett/drug-policy_b_5528644.html. Chatwin, C. Drug Policy Harmonization and the European Union. Basingstoke: Palgrave Macmillan, 2011.

Cohen, P. 'Looking at the UN, Smelling a Rat: A Comment on 'Sweden's Successful Drugs Policy: A Review of the Evidence." Amsterdam Law Forum 2, no. 4 (2010).

European Monitoring Centre for Drugs and Drug Addiction (EMCDDA). "Country List." http://www.emcdda.europa.eu/countries. - European Drug Report 2014: Trends and Developments. Lisbon: EMCDDA, 2014. http://www.emcdda.europa.eu/publications/edr/trendsdevelopments/2014.

- Annual Report 2010: The State of the Drugs Problem in Europe. Lisbon: EMCDDA, 2011. http://www.emcdda.europa.eu/publications/annual-report/2010. Garretsen, H. F. L. "Guest Editorial: The Decline of Dutch Drug Policy?" Journal of Substance Use 8, no. 1 (2003): 2-4. doi: 10.1080/146598902100001000052. Goldberg, T. "Will Swedish and Dutch Drug Policy Converge?” International Journal of Social Welfare 14, no. 1 (2005): 44-54. doi: 10.1111/j.14682397.2005.00338.x.

Gould, A. "Pollution Rituals in Sweden: The Pursuit of a Drug-free Society." Scandinavian Journal of Social Welfare 3, no. 2 (1994): 85-93. doi: 10.1111/j.1468-2397.1994.tb00062.x.Grund, JP and Breeksema, J. Coffeeshops and Compromise: Separated Illicit Drug Markets in the Netherlands. New York: Open Society Foundations, 2013. http://www.opensocietyfoundations.org/sites/default/files/coffee-shops-andcompromise-20130713.pdf. 
Ministry of Health and Social Affairs, A Cohesive Strategy for Alcohol, Narcotic Drugs, Doping and Tobacco (ANDT) Policy. Government Bill 2010/11:47. 2011. (Sweden).

Office of National Drug Control Policy. "U.S. and Sweden Host Discussions on Drug Policy Reforms under the Existing UN Conventions." Office of National Drug Control Policy White House Blog, March 14, 2014. http://www.whitehouse.gov/blog/2014/03/14/us-and-sweden-host-discussionsdrug-policy-reforms-under-existing-un-conventions.

Peil.nl. "Cannabis Opinion Polls in the Netherlands." Translated by the Transnational Institute, 2013.

http://www.druglawreform.info/images/stories/documents/Cannabis_opinion_poll _in_the_Netherlands_2.pdf.

Reinarman, C, Cohen, P, and Hendrien Kaal, L. "The Limited Relevance of Drug Policy: Cannabis in Amsterdam and in San Francisco." American Journal of Public Health 94, no. 5 (2004): 836-842.

Rolles, S. Cannabis Policy in the Netherlands: Moving Forwards Not Backwards. Transform Drug Policy Foundation, 2014.

http://www.unodc.org/documents/ungass2016/Contributions/Civil/TransformDrug-Policy-Foundation/Cannabis-policy-in-the-Netherlands.pdf.

Room, R. "Legalising a market for cannabis for pleasure: Colorado, Washington, Uruguay and beyond." Addiction 109(3) (2014): 345-351 "Senators Want

Minister's Answers on Marijuana Supply Issues.” Dutchnews.nl, July 14, 2014. http://www.dutchnews.nl/news/archives/2014/07/senators_want_ministers_answe r.ph.p.

Swedish National Institute of Public Health. 2012 National Report to the EMCDDA by the Reitox National Focal Point: "Sweden" New Development, Trends and In-Depth Information on Selected Issues. Östersund: Swedish National Institute of Public Health, 2013. http://www.emcdda.europa.eu/html.cfm/index214099EN.html.

Tham, H. "Drug Control as a National Project: The Case of Sweden." Journal of Drug Issues 25, no. 1 (1995): 113-28

United Nations Office on Drugs and Crime. Sweden's Successful Drug Policy: A Review of the Evidence. Vienna: United Nations, 2007. https://www.unodc.org/pdf/research/Swedish_drug_control.pdf. Uchtenhagen, A. "Some critical issues in cannabis policy reform". Addiction 109(3) (2014): 356-358.Van Laar, M., Cruts, G., van Ooyen-Houben, M., van der Pol, P., Croes, E., Meijer, R. and Ketelaars, T. The Netherlands Drug Situation 2013: Report to the EMCDDA by the Reitox National Focal Point. Utrecht:

Trimbos Institute, 2014. http://www.trimbos.org/ /media/Files/Gratis\%20downloads/AF1268\%20Report\% 20to\%20the \%20emcdda\%202013.ashx. 
